\title{
STEREOPSIS AND AGEING
}

\author{
L. A. WRIGHT and R. P. L. WORMALD \\ London
}

\begin{abstract}
SUMMARY
This study reports the prevalence of defective stereopsis in an elderly population. Of $\mathbf{7 2 8}$ individuals over the age of 65 who attempted a Frisby stereotest, only $27 \%$ had full stereopsis and $29 \%$ had no stereopsis. In the elderly population defective stereopsis is a common finding in the absence of any other ocular morbidity. The prevalence of defective stereopsis increased with age. This finding was noted as a part of a survey of eye health of elderly people living in an inner city. The finding was not associated with any symptoms. The significance of this finding is discussed.
\end{abstract}

To our knowledge, there are no population-based prevalence estimates of orthoptic abnormalities in the elderly. Little is known about normal binocular function in this age group although stereoacuity is considered to be an ability limited by age. ${ }^{1}$ Without knowledge of the underlying population prevalence of reduced binocular function (stereopsis), we cannot adequately interpret the significance of such a clinical finding in an elderly person.

Tests of stereopsis have been used for many years as a paediatric screening test for defects of binocular function. $^{2,3}$

In this survey a test of global stereopsis, which requires a more complex level of neural processing than local stereopsis, was selected as a simple method of testing visual cognition in an elderly population. Random-dot stereograms, such as the Frisby test, are such a global test, whereas the TNO or Titmus tests are local tests ${ }^{4}$ of stereopsis.

\section{METHOD}

As part of a pilot study the purpose of which was to improve baseline estimates of the prevalence of common eye disease in an inner city elderly population, all patients over 65 years from two general practitioner age/sex registers were invited to participate in a survey of eye health. The sample consisted of two clusters from London's inner

From: Institute of Ophthalmology, Department of Preventive Ophthalmology, 27-29 Cayton Street, London EC1V 9EJ, UK.

Correspondence to: L. A. Wright, BEd, DBO(D), Academic Unit of Ophthalmology, Western Ophthalmic Hospital, Marylebone Road, London NW1, UK. city. The two general practitioner practices which collaborated with the study serve large municipal housing estates which house mainly London-born people from the lower end of the socio-economic scale. There were a few Irish, African-Caribbean and other immigrants in this sample. The survey clinics were held in a variety of centres including a hospital-based clinic, two general practitioner surgeries and a community centre, and in the homes of those who were housebound.

A full ophthalmic examination was carried out on all those attending the survey clinics. This paper presents relevant details of the orthoptic examination only; results of the main study are published elsewhere. ${ }^{5}$

The initial examination included binocular visual acuity (wearing distance spectacle correction if normally used) at $6 \mathrm{~m}$ with Snellen test type and uniocular visual acuity at $3 \mathrm{~m}$ with the Sonksen-Silver test type. Near acuity was measured by the ability of participants to read N6 (with the normal correction if worn) with either eye at their normal reading distance. A cover test was carried out for near and distance, to check binocularity, and ocular movements were assessed in the nine positions of gaze.

The Frisby stereotest was selected as the simplest reliable method of quickly ascertaining stereoacuity. The test is a hybrid test based on random-dot stereograms which give the appreciation of depth by binocular disparity. Random-dot stereograms appear to be the test least subject to non-stereoscopic cues, ${ }^{6}$ although the Frisby test does not completely exclude monocular depth cues. The test consists of three Perspex plates of varying thicknesses $(6 \mathrm{~mm}, 3 \mathrm{~mm}$ and $1 \mathrm{~mm})$. On one surface of each plate are four squares each $6 \mathrm{~cm}$ in size with blue triangles on them. In the centre of one square of each of the three plates is a $3 \mathrm{~cm}$ circle printed on the reverse giving the impression of a 'hole' or 'a circle sticking out'? The Frisby test was selected for its ease of presentation in this age group because it does not require any additional spectacles to create the stereoscopic effect. Because most people in this age group require presbyopic correction, additional red/ green or polarised lenses required by the Wirt or TNO tests would have been clumsy to administer. The test was explained in a systematic way to all participants and in most cases the concept of the test was quickly grasped. In 
the cases where there was any doubt about full comprehension of the test, it was recorded as invalid.

The plates were held at the individual's normal reading distance (about $40 \mathrm{~cm}$ in practice) at which the disparities of the plates are 340 seconds, 170 seconds and 55 seconds. Because allowance had to be made for the participants to use their own reading glasses, we could not strictly control the distance at which the test was delivered. The distance at which optimum near vision could be obtained was used but this was not formally measured. The participant was asked to hold his or her head in one position to avoid extraneous monocular clues and the observer always held the plates perpendicular to the individual's gaze.

Because exact stereoacuity measurements vary with the reading distance, the results were recorded only as 0 (no plates seen but the test adequately understood), 1 (the $6 \mathrm{~mm}$ plate being seen), 2 (the $3 \mathrm{~mm}$ plate being seen) or 3 (the $1 \mathrm{~mm}$ plate being seen). All tests were performed using standard background illumination.

\section{RESULTS}

A response rate of $60 \%$ was achieved and 784 people were examined. By conducting a telephone questionnaire on a sample of the non-attenders, basic information on a further $20 \%$ has been gathered. On 728 of these participants measurement of stereopsis was attempted (56 not tested). In 43 the test was invalid because of lack of comprehension, giving a total of 719 persons for whom the test was recorded. In each age group females outnumbered males by $3: 2$, but there was no difference in the prevalence of abnormalities by sex.

Figure 1 shows the overall prevalence of stereopsis by grades. Only $27 \%$ of the study population had full stereopsis, seeing all three plates, and $23 \%$ had no stereopsis. The remaining $44 \%$ had intermediate grades. In 99 participants from the total sample of 784 there are no stereopsis results or invalid results. In this group 56 were not tested for stereopsis because the test was unavailable at this time ( 31 were home visits). In 41 of the 43 invalid tests there was reduced distance vision in one or both eyes. Only one of this 43 had N6 in each eye.

In the total sample there were 455 people with $\mathrm{N} 6$ both

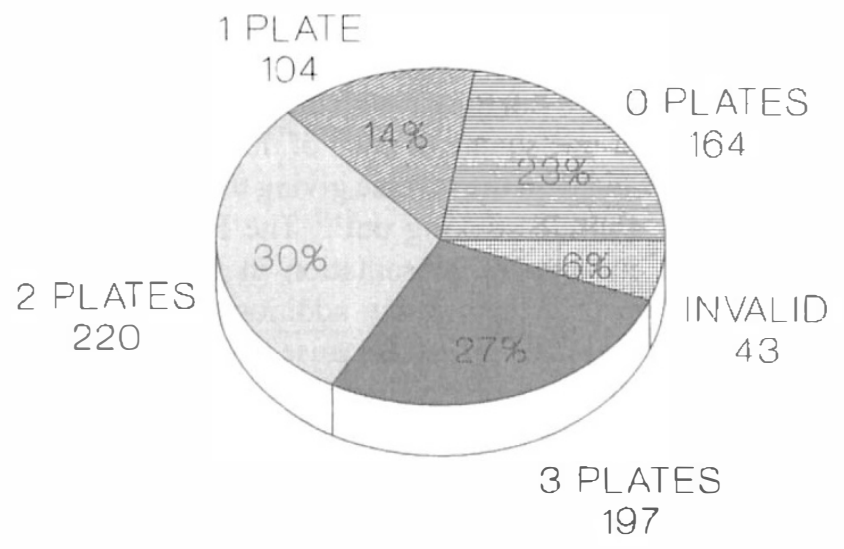

Fig. 1. Crude prevalence of stereopsis grades in 728 individuals over 65 years of age. eyes $(58 \%)$. Thirty-eight of this group are excluded from the stereopsis results for the following reasons: 16 not tested, 1 invalid test due to failed comprehension, 21 with a history of ocular pathology or surgery which may have accounted for the loss of stereopsis. Of these, there were 6 who had squint and/or amblyopia, 3 who had anisometropia, 10 who had previously undergone cataract surgery and were either aphakic or had intraocular lenses, and 2 who had had previous retinal detachment repair. The prevalence of squint/amblyopia was $4 \%$ in the sample $(n=784)$.

The age-specific prevalences of the different grades of stereopis as defined by number of plates seen is given in Fig. 2 together with a data table of the frequencies. This represents all those persons in the sample for whom all possible underlying explanations for poor stereopsis have been excluded and also could see N6 with both eyes. The strong age-related trend persists despite this adjustment. Fifty per cent of the 65-69-year-olds have full stereopsis while nearly $50 \%$ of those over 80 have absent or poor stereopsis.

The Mantel-Haenszel chi-squared test for trend shown in Table I confirms that there is a strong age-dependent effect. For this analysis, full stereopsis was considered present if plates 2 or 3 were seen, and absent if 0 or 1 were seen. The Odds Ratio for loss of stereopsis for the 70-75year-olds is $2.57(p=0.01)$ and for the $80+$ group is 7.54 $(p=<0.001)$, taking the 65-69-year-old group as baseline risk.

Table II shows the status of the $329(42 \%)$ of the remaining sample who were excluded because they did not have N6 vision both eyes. Of these $25.5 \%$ had full stereopsis (considered present if plates 2 or 3 were seen) despite having reduced near vision. There was no agedependent effect in this group.

The prevalence of glaucoma in the total sample was $4 \%$. There were 7 participants with definite glaucoma who could read N6 with both eyes in which stereopsis was measured. Only one of these 7 had defective stereopsis.

\section{DISCUSSION}

It has previously been recognised that patients undergoing surgery for cataract or retinal detachment appear to lose

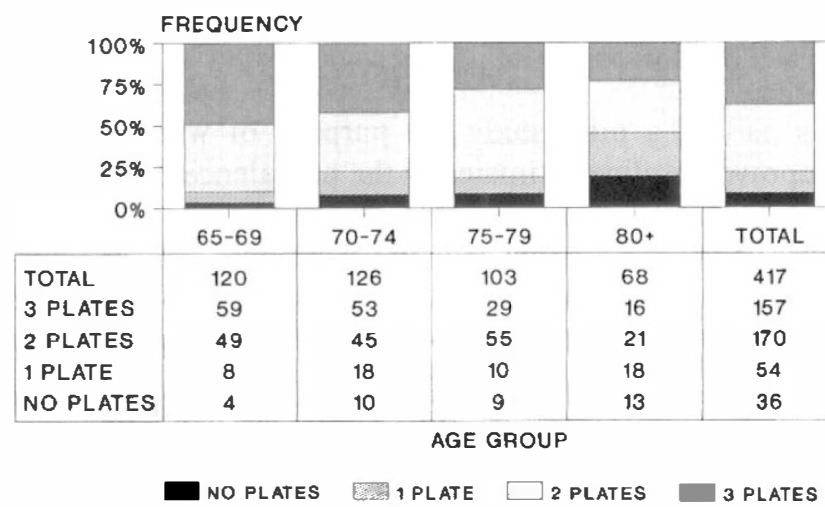

Fig. 2. Relative frequency of stereopsis grade by age group, for those with N6 both eyes. 
Table I. Stereopsis by age group

\begin{tabular}{cccccc}
\hline $\begin{array}{c}\text { Age } \\
\text { bands }\end{array}$ & $\begin{array}{c}\text { Full } \\
\text { stereopsis }\end{array}$ & $\begin{array}{c}\text { Absent } \\
\text { stereopsis }\end{array}$ & $\begin{array}{c}\text { Odds } \\
\text { ratio }\end{array}$ & $\begin{array}{c}95 \% \\
\text { confidence } \\
\text { limits }\end{array}$ & $\begin{array}{c}p \\
\text { value }\end{array}$ \\
\hline $65-69$ & 108 & 12 & - & - & - \\
$70-74$ & 98 & 28 & 2.57 & $1.13-6.43$ & 0.01 \\
$75-79$ & 84 & 19 & 2.04 & $0.89-5.09$ & 0.07 \\
$80+$ & 37 & 31 & 7.54 & $3.30-18.8$ & $<0.001$ \\
\hline
\end{tabular}

Test for trend 23.99, $\mathrm{p}=<0.001$.

some element of binocular function, ${ }^{8,9}$ and in cases of optic neuritis ${ }^{10,11}$ stereopsis may be defective. Two reports in the literature suggest an association between loss of stereopsis and glaucoma. ${ }^{12,13}$ There were too few cases of glaucoma in this study to make useful comment. Recently loss of stereopsis in Alzheimer's disease has been noted. ${ }^{14}$

Previous reports suggesting that stereopsis does not change appreciably with increasing age are based on small samples of the older age groups. ${ }^{15-17} \mathrm{Jani}^{18}$ noted an increase in stereoacuity from ages 9 to 20 years and then a considerable reduction of stereoacuity over the age of 40 in a volunteer study of stereopsis using the Diastereo test. The criteria for analysis in this study are very different and the two cannot be compared.

Heron et al. ${ }^{19}$ reported a comparison of the absolute threshold of stereopsis in adults and children using four different methods, one of which was the Frisby test. They concluded the Frisby test revealed the highest levels of stereoacuity with least variability for all age groups but that there was variability between children (aged 3-7 years) and young adults (aged 18-22 years) when tested with the Frisby. All but one of the 51 young adults tested could see the $1 \mathrm{~mm}$ plate (plate 3 ) of the Frisby at $40 \mathrm{~cm}$.

Williams et al. ${ }^{20}$ reported a prevalence of $2.1 \%$ and $3.2 \%$ defective stereopsis in a large study of children aged 7 and 11 years respectively tested with a random stereotest. A further $10-16 \%$ had only moderate levels of stereoacuity. They concluded that defective stereopsis was clearly associated with manifest squint, and/or poor vision. Neither of these factors can account for the reduced stereopsis in the adjusted prevalence in our sample where squint, amblyopia and poor near vision are excluded.

Similar results were given by Richards, ${ }^{21}$ who tested 150 students with random-dot stereograms and found about $4 \%$ were unable to see the cue offered by the disparity, while a further $10 \%$ had difficulty. He therefore estimates that $14 \%$ of the population lack the full ability to use

Table II. Stereopsis status of 329 who could not read N6 with both eyes

\begin{tabular}{lccc}
\hline Stereopsis grade & Total & Age 65-69 & Age 75+ \\
\hline Not tested & 40 & 7 & 33 \\
Invalid & 42 & 19 & 23 \\
0 & 120 & 50 & 70 \\
1 & 43 & 17 & 26 \\
2 & 47 & 25 & 22 \\
3 & 37 & 16 & 21 \\
Total & 329 & 134 & 195 \\
\hline
\end{tabular}

binocular disparities to judge depth. In our total sample $77.5 \%$ lacked full stereopsis, and in the sample of 417 with N6 in both eyes and no pathology $62.3 \%$ still lacked full stereopsis (plate 3).

Results of papers describing detailed stereoacuity recorded are not directly comparable to this study because we did not measure stereopsis in terms of seconds of arc but only in terms of number of plates seen at the normal reading distance. For this to explain the increased prevalence of poor stereoacuity with age, one would have to hypothesise that the reading distance also increased with age; this was not observed clinically. A tendency towards undercorrected myopia (probably due to nuclear sclerosis) was found in the whole sample, especially in the older age group.

Formal repeatability studies for the Frisby test were not undertaken for this study because it was a cross-sectional study and there was not an opportunity to retest individuals on a different occasion. A problem with the Frisby test is that multiple exposure may lead to a learning effect which may allow the subject to identify the plates by nonstereoscopic clues. ${ }^{22}$

Defective stereopsis did not give rise to any subjective symptoms being reported in the survey. However, no specific questions were asked with regard to the possible effects of reduced stereopsis such as difficulty with steps or pouring tea. Cohn and Lasley ${ }^{1}$ doubt the validity of stereoacuity as a measure of stereo-capability in the elderly although they present no evidence to support this view. The functional significance of loss of stereoacuity as measured by the Frisby test in the elderly needs further investigation.

In seeking some explanation for reduced stereopsis, one might suppose that the strong age-related increase in prevalence is related to an age-related decrease in cerebral function. Cohn and Lasley ${ }^{1}$ suggest neural effects of ageing may be the reason for reduced stereopsis with age. It is of interest that there may be an association between loss of stereopsis and onset of dementia; recently it has been shown that defective stereopsis occurs in Alzheimer's disease ${ }^{14}$ independent of age. In 5 out of 8 of these Alzheimer's cases reported the patients did complain of visual symptoms although there was no loss of visual acuity. It was originally thought that the visual difficulties in patients with dementia were cerebral in origin, but Sadun and Bassi $^{23}$ show that there is specific damage to the largest size of retinal ganglion cells, the M-cells, as these may be more susceptible to certain pathophysiological processes. This appears to occur before there is a reduction in visual acuity or evidence of optic neuropathy clinically. It is possible that loss of stereopsis could be the clinical manifestation of this nerve fibre loss. Whether this accounts for the increasing prevalence of abnormal binocular function with age requires further investigation.

We should like to thank all the orthoptic students and optometrists who assisted with the Inner City Eye Study (ICES) where this data was collected. Thanks also are due to Drs. Beaumont and Hurwitz, and to Professor Andy Haines, Drs. Cripwell, Davidson and Hunt for allowing us to study their patients. 
Key words: Ageing; Frisby test; Stereopsis.

\section{REFERENCES}

1. Cohn TE, Lasley DJ: Visual depth illusion and falls in the elderly. Clin in Geriatric Med 1985, 3: 608.

2. Simons K, Reinecke RD: Reconsideration of amblyopia screening and stereopsis. Am J Ophthalmol 1974, 78: 707-13.

3. Broadbent $\mathrm{H}$, Westall $\mathrm{C}$ : An evaluation of techniques for measuring stereopsis in infants and young children. Ophthalmic Physiol Opt 1990, 10: 3-7.

4. Zanoni D, Rosenbaum AL: A new method for evaluating distance stereo acuity. J Pediatr Ophthalmol Strabismus 1991, 28: 255-60.

5. Wormald RPL, Wright LA, Courtney P, Beaumont B, Haines AP: Visual problems in the elderly population and implications for services. $\mathrm{Br}$ Med J 1992, 304: 1226-9.

6. Frisby JP, Mein J, Saye A, Stanworth A: Use of random-dot stereograms in the clinical assessment of strabismic patients. Br J Ophthalmol 1975, 59: 545-52.

7. Frisby JP: The Frisby stereotest: amended instructions. $\mathrm{Br}$ Orthopt J 1980, 37: 108.

8. Galin MA, Baras I: Stereoscopic acuity measurement in aphakia. Am J Ophthalmol 1978, 86: 825-7.

9. Katsumi O, et al: Binocular function in unilateral aphakia. Ophthalmology 1988, 95: 1088-93.

10. Freidman JR, Kosmorsky GS, Burde RM: Stereoacuity in patients with optic nerve disease. Arch Ophthalmol 1985, 103: $37-8$.

11. Griffiths PG, Voller J: Stereo-acuity in optic nerve disease. Br Orthopt J 1988, 45: 23-5.
12. Bassi CJ, Galanis JC: Impairment of binocular vision may indicate early glaucomatous damage. ARVO Abstr 1990 (Mar), 31: 4, 1132-28.

13. Liebergall D, Solomon S, Schultz J: The effects of chronic open angle glaucoma on stereoacuity. ARVO Abstr 1990 (Mar), 31: 4, 1132-29.

14. Kiyosawa M, et al: Alzheimer's disease with prominent visual symptoms. Ophthalmology 1989, 96: 1077-86.

15. Hofstetter HW, Bertsch JD: Does stereopsis change with age? Am J Optom Physiol Optics 1976, 53: 664-7.

16. Greene HA, Madden DJ: Adult age differences in visual acuity, stereopsis, and contrast sensitivity. Am J Optom Physiol Optics 1987, 64: 749-53.

17. Yekta AA, Pickwell LD, Jenkins TCA: Binocular vision, age and symptoms. Ophthalmic Physiol Opt 1989, 9: 115-20.

18. Jani SN: The age factor in stereopsis screening. Am J Optom 1966, 43: 653-7.

19. Heron G, Dholakia S, Collins DE, McLaughlan H: Stereoscopic threshold in children and adults. Am J Optom Physiol Optics 1985, 62: 505-15.

20. Williams S, Simpson A, Silva PA: Stereoacuity levels and vision problems in children from 7 to 11 years. Ophthalmic Physiol Opt 1988, 8: 386-9.

21. Richards W: Stereopsis and stereoblindness. Exp Brain Res 1970, 10: 380-8.

22. Frisby JP: Random-dot stereograms. Br Orthopt J 1974, 31: $1-8$.

23. Sadun AA, Bassi CJ: Optic nerve damage in Alzheimer's disease. Ophthalmology 1990, 97: 9-17. 